\title{
Identifying Opportunities \& Developing Models of Environmental Education from an Indian Perspective
}

\author{
Tauseef Siddiqui Zia ${ }^{1} \&$ Pramod Pathak ${ }^{2}$ \\ ${ }^{1} \mathrm{PhD}$ Student, Indian School of Mines, Dhanbad, India. \\ ${ }^{2}$ Professor, Indian School of Mines, Dhanbad, India.
}

\begin{abstract}
As we are entering in the next millennium it is essential for our experts to review the environmental education curriculum and training modules and materials, this will help in closing the gap between what environmental experts know and what the public and students needs to know. Current environmental education and training programs are stressed on controlling, remediation or clean up environmental problems. Because more than $90 \%$ of the world population growth and much of the economic growth expected in the next 40-50 years will be in developing countries it is important that environmental education must be made a priority.

Therefore, teachers need continuing awareness, environmental education and related training programs to keep up with the complexity of environmental problems and technologies and strategies to reduce environmental risks. The paper focuses in developing working model of Environmental Education (EE) in the formal sector and to evaluate and statically analyze the EE knowledge perception of the different sectors of the society through structured questionnaire surveys of teachers, students and literate citizens of the urban area. This paper tries to find out the barriers and strategies for promotion of EE in India.
\end{abstract}

\section{General Terms}

To evaluate different successful models of Environmental Education especially with respect to sustainability that is currently being adapted in India at present and proposes strategies for improving the same.

\section{Indexing terms}

Attitudes; Environmental Education (EE); environmental knowledge; skills; student engagement.

\section{Academic Discipline And Sub-Disciplines}

Management Studies and Environmental Education

\section{Subject Classification}

Environment Management and Environmental Awareness

\section{COVERAGE}

i. To study the importance of the environmental education with specific emphasis to sustainability and various environmental education patterns in the educational institutions in India.

ii. To study all the identified successful models and best sustainability practices undertaken by the schools/colleges. This not merely for the purposes of improving Environmental Education but also to understand how different theoretical processes have actually been put into practice to make a place, such as a school/colleges, a grounds of sustainable practices.

iii. To identify solutions to the above and disseminate the same.

\section{TYPE (METHOD/APPROACH)}

For any of the study or research, quantitative data will be collected in the form of questionnaire or survey. The data or information to the study is collected by conducting the Mail Surveys, Online Surveys, Paper Surveys Panel Research and Telephone Surveys. This method creates the numerical data, if not the data will be converted to the numerical in the method of statistical evaluation. At the same time, qualitative data is gathered in the form of interviews and the respondents are provided an option to descriptively present their ideas on a specific subject.

\section{INTRODUCTION}

Environmental Education - Indian Scenario

The concerns regarding the environment started to arise due to the numerous technological developments and its application resulted in an extreme conversion of the environmental condition. The systematized global determinations began with the first conference of United Nations on the Human environment which opened at Stockholm during June 1972. As a result, the UNEP (United Nations Environmental Program) was created and IEEP (International Program in Environmental Education) was proposed by UNESCO and UNEP during January 1975 (Sonowal, 2009).

India, as an outcome of the Stockholm summit 1972; merged the environmental distress in the constitution through the 42nd Amendment during 1976 as an initiative towards fighting against environmental disaster. In the planes, strategies and policy statements, environmental concern became precedent, particularly after 1980 with the institution of a full - fledged Ministry of Environment and forests.

In India, the increasing anxiety on the Environmental Education, gained and enlarged its momentum whereas its significance was documented by the Government and strategies were planned consequently in order to introduce the Environmental Education in schools (Sonowal, 2009).

High population growth and subsistence agriculture, eventually lead to forest degradation, deforestation, soil erosion and loss of biodiversity. These environmental problems are further compounded by illiteracy, lack of 
conservation awareness, financial and technical constraints and wrong policy on part of the government. EE gets least priority because other immediate development issues become more pressing for the government. In India more than $90 \%$ states have now developed some type of environmental education guidelines and course curriculum at the level of schools, colleges and universities. The UGC has made it compulsory to all universities and colleges in India to introduce a compulsory paper of environmental studies at undergraduate level as per the directives of the Hon'ble Supreme Court of India. (UGC DO No. F.131/2000 (EA/ENV/COSI) 24 July 2002).

\section{METHOD}

In this research, we examined the views of different sectors of the society like teachers, students, and general public, which further helps in developing a working model of EE in formal sector and tries to find out the barriers and constraints in the promotion of EE in India.

The written questionnaire was originally developed in English with the help of literature survey. Before the formal survey was conducted, several Indian College and High School teachers in Delhi reviewed the instrument and recommended small revisions and reviews. The questionnaire consisted of five questions related to basic EE assessment, the present statistical analysis are developed with the help of Summated Scales (or Likert- type Scales) by utilizing the item analysis approach wherein a particular item is evaluated on the basis of how well it discriminates between those persons whose total score is high and those whose score is low. These items or statements that best meet this sort of discrimination test are included in the final instrument.

Thus summated scales consist of a number of statements, which express either a favorable or an unfavorable attitudes towards the given object to which the respondent is asked to react. The respondents agreement or disagreement among each other in the instrument. Each response is given a numerical value/score, indicating its favorablenessunfavourableness, and the scores are totaled to measure the respondent's attitude. In other words, the overall score represents position on the continuum of favorablenessunfavourableness towards an issue.

Most frequently used summated scales in the social attitudes follow the pattern devised by Likert. For this reason, they are often referred to as Likert- type scales. In a Likert scale, the respondent is asked to respond to each of the statements in terms of several degrees, usually five degrees ( but at times 3 or 7 may also be used) of agreement or disagreement. For example, when asked to express opinion whether one considers his job quite pleasant, the respondent may respond in any of the following ways: (i) strongly agree (ii) agree (iii) undecided (iv) disagree (v) strongly disagree (Table 1).

Table 1: Questionnaire on Environmental Values and Attitudes

\begin{tabular}{|c|c|c|c|c|c|c|}
\hline \multirow{2}{*}{\multicolumn{2}{|c|}{ Environmental issues }} & \multicolumn{5}{|c|}{ Public response } \\
\hline & & \multirow{2}{*}{$\begin{array}{l}\text { Strongly } \\
\text { agree }\end{array}$} & \multirow[t]{2}{*}{ Agree } & \multirow[t]{2}{*}{ No opinion } & \multirow[t]{2}{*}{ Disagree } & \multirow{2}{*}{$\begin{array}{l}\text { Strongly } \\
\text { disagree }\end{array}$} \\
\hline Q.1 & $\begin{array}{l}\text { The balance of nature is very delicate and } \\
\text { easily upset }\end{array}$ & & & & & \\
\hline Q.2 & $\begin{array}{l}\text { When humans interfere with nature, it often } \\
\text { produces disastrous consequences }\end{array}$ & & & & & \\
\hline Q.3 & $\begin{array}{l}\text { The earth is like a spaceship with only limited } \\
\text { room and resource. }\end{array}$ & & & & & \\
\hline Q.4 & $\begin{array}{l}\text { We are approaching the limit of the number of } \\
\text { people that India can support }\end{array}$ & & & & & \\
\hline Q.5 & $\begin{array}{l}\text { There are limits of growth beyond which our } \\
\text { industrialized society cannot expand }\end{array}$ & & & & & \\
\hline
\end{tabular}

We find that these five points constitute the scale. At one extreme of the scale, there is strong agreement with the given statement and at the other, strong disagreement, and

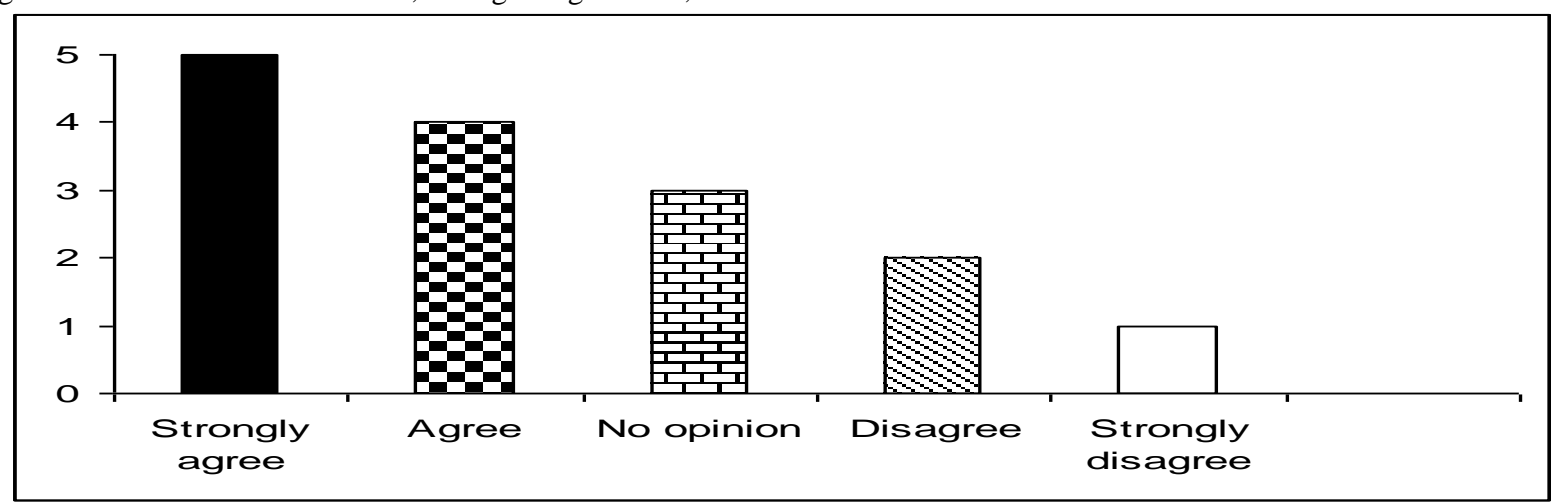

Figure 1: Likert scale of social attitude. 


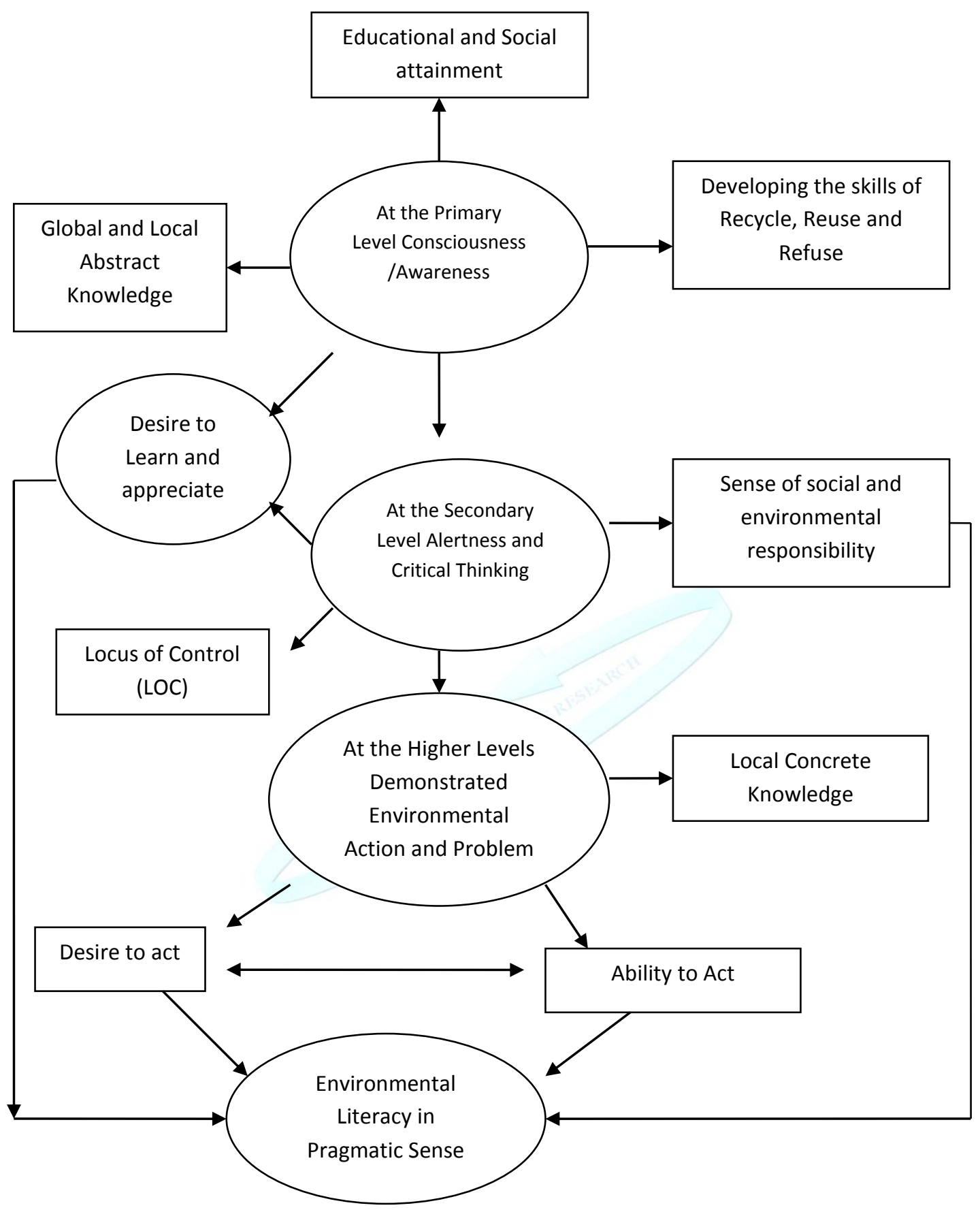

Figure 2: Working model for formal environmental education.

\section{COMPONENTS OF THE MODEL}

In order to design a 'working model' of environmental education numerous components are involved. There are different phases of one's education that is at primary level, secondary level, and higher level. There are different approaches which are analysed in the present model and are explained in the subsequent sections.

\subsection{At the Primary Level}

The students of class (1st to 5th) are in their immature phase and the school administration must focus perpetually in developing the students a more educational and social 
attainment towards studies and telling them the basic principles of Recycle, Reuse, Recover and Refuse. The teachers should try to give them the basic and abstract knowledge of both Global and Local environmental issues, which indirectly helps the students to develop the tinge of Consciousness/Awareness about the environment and its significance in their lives and surroundings.

Children have always had an immediate interest in the trees, bugs and birds outside their classroom in this early phase of their lives. Teachers have traditionally used the outdoors as a way to make science come alive and to bring together a variety of disciplines, such as mathematics and social studies. Teachers report that environmental education captures their students' attention more readily than many other topics. Given the widespread concern over academic achievement in Indian schools, especially in science and mathematics, environmental education holds great promise for boosting the quality of learning in our classrooms at this early stage and hence the first part of the proposed model solely focuses in developing a desire to learn and to appreciate the nature.

\subsection{At the Secondary Level}

The students of class (6th to 10th) are in their transition phase of their educational spectrum. They are having a sense of social and environmental responsibility and the teachers must focus in that area, as to how to motivate and inspire the students in that context, also to groom them to think critically and creatively towards the issues of sustainable development and to develop an understanding towards both global and local environmental issues. The perpetual focus must be towards developing a sense of 'Locus of Control'. Locus of control (LOC) is a general concept which can be applied in any context to individual's perception of their ability to bring about change through their own behaviour. If the individual believes that events or outcomes of situations are the direct results of his/her actions, he/she has an internal LOC. In a meta-analysis of research on environmentally responsible behaviour, Hines et al. (1987) found that an internal LOC is likely to affect/change and can have an ever lasting impact on the students attitudes and behaviour of the students. Students with an external LOC do not try to bring about change because they thought they are helpless and are unable to do anything.

Table 2: One-way analysis of variance (ANOVA) of views of different social communities (Teachers, Students and General Public) on Environmental Education.

\begin{tabular}{|l|l|l|l|l|l|l|}
\hline ANOVA FOR Q. 1 & & & & & & \\
\hline Source of Variation & SS & df & MS & F & P-value & F crit \\
\hline Between communities & 37.26667 & 2 & 18.63333 & 24.68271 & $1.14 \mathrm{E}-09$ & 3.073763 \\
\hline Within communities & 88.325 & 117 & 0.754915 & & & \\
\hline & & & & & & \\
\hline Total & 125.5917 & 119 & & & & \\
\hline
\end{tabular}

\begin{tabular}{|l|l|l|l|l|l|l|}
\hline ANOVA FOR Q. 2 & & & & & & \\
\hline Source of Variation & SS & df & MS & F & P-value & F crit \\
\hline Between communities & 13.06667 & 2 & 6.533333 & 9.056872 & 0.00022 & 3.073763 \\
\hline Within communities & 84.4 & 117 & 0.721368 & & & \\
\hline
\end{tabular}

\subsection{At the Higher Level}

This category includes a wide range, the undergraduates, graduates, postgraduates and lastly the student in higher secondary. At this juncture of their lives they are pragmatically and theoretically very sound pertaining to the issues of Environmental education, the only area which needs to be worked upon is of giving the concrete and in depth knowledge of the local issues, to inspire them and to develop in them the desire to act according to the situation, a demonstrated environmental action needs to be taken by them.

Perception of environmentally responsible behaviour as the social norm may cause social pressure on individuals to conform; 'If a social norm for environmentally responsible behaviour existed, more students might behave responsibly, even if they do not have strong attitudes about environmental protection' (Newhouse, 1990). In other words, environmental behaviour may be influenced by what students believe is 'the doing thing'. Traditionally, environmental education has been as concerned with promoting "responsible environmental behaviour" as it has been with teaching children about the environment. However, there is no consensus among parents or the community at large on what constitutes environmentally responsible behaviour or to what extent schools should encourage students to take action on behalf of an environmental cause. The field should place its emphasis on building environmental knowledge, not on promoting a particular kind of behaviour.

The present model of formal education (Figure 2) is especially designed in terms of Indian context but can be replicated in other developing countries as well; it can also be helpful for the teachers, regulators and policy makers to form a strategy towards environmental education.

\section{RESULTS AND DISCUSSIONS}

Statistical analysis of structured questionnaire of teachers, students and general people

Views of different communities (teachers, students and general people) of a social platform regarding five issues of environmental education in Indian perspective are summarized in Table 2 and 3. 


\begin{tabular}{|l|l|l|l|l|l|l|}
\hline & & & & & & \\
\hline Total & 97.46667 & 119 & & & & \\
\hline
\end{tabular}

\begin{tabular}{|l|l|l|l|l|l|l|}
\hline ANOVA FOR Q. 3 & & & & & & \\
\hline Source of Variation & SS & df & MS & F & P-value & F crit \\
\hline Between communities & 32.26667 & 2 & 16.13333 & 11.21402 & $3.5 \mathrm{E}-05$ & 3.073763 \\
\hline Within communities & 168.325 & 117 & 1.438675 & & & \\
\hline & & & & & & \\
\hline Total & 200.5917 & 119 & & & & \\
\hline
\end{tabular}

\begin{tabular}{|l|l|l|l|l|l|l|}
\hline ANOVA FOR Q. 4 & & & & & & \\
\hline Source of Variation & SS & df & MS & F & P-value & F crit \\
\hline Between communities & 92.51667 & 2 & 46.25833 & 37.94059 & $1.99 \mathrm{E}-13$ & 3.073763 \\
\hline Within communities & 142.65 & 117 & 1.219231 & & & \\
\hline & & & & & & \\
\hline Total & 235.1667 & 119 & & & & \\
\hline
\end{tabular}

\begin{tabular}{|l|l|l|l|l|l|l|}
\hline ANOVA FOR Q. 5 & & & & & & \\
\hline Source of Variation & SS & df & MS & F & P-value & F crit \\
\hline Between communities & 82.11667 & 2 & 41.05833 & 34.44219 & $1.73 \mathrm{E}-12$ & 3.073763 \\
\hline Within communities & 139.475 & 117 & 1.192094 & & & \\
\hline & & & & & & \\
\hline Total & 221.5917 & 119 & & & & \\
\hline
\end{tabular}

Table 3: Average views of teachers, students and general public on issues regarding environmental education in Indian perspective

\begin{tabular}{|l|l|l|l|l|l|}
\hline & Q.1 & Q.2 & Q.3 & Q.4 & Q.5 \\
\hline Teachers & $4.4^{\mathrm{a}}$ & $4.2^{\mathrm{a}}$ & $3.7^{\mathrm{a}}$ & $4.6^{\mathrm{a}}$ & $4.3^{\mathrm{a}}$ \\
\hline Students & $3.2^{\mathrm{b}}$ & $3.5^{\mathrm{b}}$ & $2.6^{\mathrm{b}}$ & $3.2^{\mathrm{b}}$ & $2.5^{\mathrm{b}}$ \\
\hline General people & $3.3^{\mathrm{b}}$ & $3.5^{\mathrm{b}}$ & $2.6^{\mathrm{b}}$ & $2.5^{\mathrm{c}}$ & $4.2^{\mathrm{a}}$ \\
\hline
\end{tabular}

* Different letters in a column indicate a significant difference at $\mathbf{p}<0.05$.

The data were analyzed by one-way analysis of variance (ANOVA) to compare average views of different communities and Duncan multiple range test was carried out to find significant differences between individual views. For the first three questions, the average views of teachers differ significantly than students and general people. However, in case of Q. 4 regarding carrying capacity of our nation both teachers and general people gave more or less the same opinion. Nevertheless, in issues like limit of industrial growth (Q. 5) the opinion of all the surveyed communities differ significantly from each other. In general, the survey results of the first three questions related to balance of nature, human interference with nature, and about the limited resources on earth, depict that the teachers are more concerned about the environment, its control, management and conservation, but on their counterpart the students and general public figure out a very pathetic picture about their level of consciousness and commitment towards the basic environmental ethics and attitudes, a lot of work to be done in the field of environmental education in India and we have to move a step forward to take a demonstrated action and to think in a manner so that the students and the general public comes to know about the grave environmental problems and to make
EE a learner-centered, providing students with opportunities to create their own understandings through hands-on, minds-on investigations. Learners are engaged in direct experiences and are challenged to use higher-order thinking skills, for each environmental issue there is not just one right answer or solution--there are many perspectives and much uncertainty. Environmental education cultivates the ability to recognize uncertainty, envision alternative scenarios, and adapt to changing conditions and information regarding these grave problems , the only way the EE programs can make firm ground in India only when the citizens comes to know how should they can contribute towards the nature.

The results of the last two questions, which are related to over population and limits of growth in Industrialized society again depicts the same picture where teachers know exactly the drawbacks of overpopulation as it is the root cause of all the major interrelated evils that exits in our country like (poverty, crime, unemployment etc) all these are directly related to the population explosion. But on their counterpart the students and the general public thinks in a very unconstructive manner and thinks that it is not the issue of population that is eating up the economic growth of 
the society but there are some other factors which affects the prosperity.

Finally, this study is limited by the fact that it only measured reported environmental ethics and attitudes patterns of the teachers, students and general public, the other issues related to environment are not touched. The data could be biased based on individual perceptions of changed behavior of teachers, students and general public. Future research on the larger sample size should give some robust empirical results about the environmental ethics and attitudes on sustainable development.

Barrier and Constraints/drawbacks

Above all, the techniques adopted in Environmental Education have not helped people realize that individuals can bring about an optimistic change and need to improve their own surroundings and communities by becoming accountable and proactive, 'community minded' society. The main problems in EE that India is facing can be summarized as follows:

1) Curriculum load: There is a tremendous pressure from parents and community that school curriculum has become very heavy and is responsible for development of stress among students and thereby affecting their normal developments. The problem of curriculum load is a complex one and has its roots in many related issues.

2) Preparation of Teachers: Pre-services preparation and In-service training of teachers are major problems in implementation of curriculum. Given the huge number of teachers and geographical character of the country, management of in-service programmes is indeed a challenge.

3) Methods of Assessment: The present assessment/evaluation system in science education is a major bottleneck in bringing improvement in the education system of our country. Unfortunately, what is not relevant to examination is not considered relevant in teaching and learning. Framework of assessment used is not conducive to the development of problem-solving skill among the pupils - given the fact that instruction is mainly assessment-driven in India. Further, assessment of practical work is not attached much importance resulting in utter neglect of practical work in school education.

The way Environmental Education is being dealt with in schools in India therefore, needs to be completely revamped and clearly defined methods should be laid out for easy applicability in schools, bearing in mind the following aspects, which have to be the foundation of this change:

a) To work more towards a cultural change that leads us ultimately into living more sustainable lives.

b) To venture ecological education a core subject of our education and also includes environmental perception into the other subjects.

c) To transform thinking patterns that the earth is ours for the taking. We have to understand more about the nature of this finite earth and then work out ways and regulate ourselves to live sustainably and in harmony with it.

d) To become more community minded citizens.
Strategies for Promotion of EE

EE has obtained momentum but has not been able to make the quantum leap towards preventing, stopping and reversing environmental degradation. Some of the reasons given below may help explain the situation and describe the obstacles for $\mathrm{EE}$ in the region.

1) The problems of EE are universal in nature and directly related to the complex problems of development process, persistent poverty, growing population and environmental degradation.

2) Environmental themes are widely integrated into formal education courses. Yet we do not know how effective they are in real-life situations, or if formal education is the best way to achieve a sustainable society, a society that meets the needs of the present generation without compromising the needs of future generations. Research is necessary to provide the answers.

3) Numerous NGOs and other organizations are involved in the field of EE. Any organization can boast that it is successfully undertaking $\mathrm{EE}$ activities. Nevertheless, there is also duplication of activities and competition among different organizations. When this is so, then it is necessary to determine their status and synergize their strengths in promoting EE in the region.

4) Finally, merely raising awareness is not enough to promote EE. EE must go beyond awareness raising. It must inspire interest, encourage people to pilottest new ideas, and then, based on their evaluation, adopt them as integral parts of their lives. For this, more projects and actions are required to provide role models for successful EE efforts.

\section{CONCLUSIONS}

Though various measures have been initiated by various governmental and non-governmental agencies to promote and foster environmental education, the overall achievement has not been satisfactory so far. Existing EE programs only generate awareness and sensitivity but do not focus at the skill and attitude levels. School children do not get opportunities to develop skills to analyze and evaluate local, regional, or national environmental problems or issues. Thus, it seems that the existing formal education programs have failed to inculcate a sense of ownership and empowerment in schoolchildren.

As in all other areas, education and awareness raising efforts are critical in shaping people's perception, attitudes, and behavior towards environmental concerns. These efforts enable individuals to appreciate better environmental policies, legislation and regulation, and foster individual responsibility toward sustainable resource management and development.

Documenting successful models and best practices of Environmental Education with a focus on sustainability will be beneficial for schools, educators, researchers in the field and environmentalists since the teachers yet do not know how to go about imparting EE. It would also help National Council for Education Research and Training (NCERT) provide resource material as per the National Policy. However, the biggest beneficiary and greatest victor in due course will be planet earth! Imagine if all the 
sustainable models of environmental education are put into practice by millions of students all over India, it becomes a part of their lives and brings forth an attitudinal change well that will be a revolution of sorts!

Lastly, it can be concluded that though the existing EE programs do not seem to be satisfactory, the future looks promising. Moreover in planning to develop school curricula on conservation education at the national level. It is hoped that these steps will bring desirable results in the future in sustaining precious natural resources of India.

If you are planning* for a year-sow rice* for ten years plant trees* for a hundred years - educate people A Chinese Proverb.

"Let us sum up by recalling the new Panchsheel of the new millennium that we should launch: a) Child centered education; b) Woman centered family; c) Human centered development; d) Knowledge centered society; and e) Innovation centered India."

This mandate will help lead India into a knowledge society. The future India would develop into a learning society with scientific temper.

\section{REFERENCES}

[1] Abe, O. and Bishnu Bhandari. 1999. An overview of environmental education in the Asia and Pacific region. Proceedings of the International Conference on Environmental Education in the Asia-Pacific Region, Yokohama, Japan, 27-28 February 1999.

[2] Arora, G.L. Child centred education for learning without burden. Gurgaon, Haryana, Krishna Publishing Company, 1995.

[3] Arora, G.L.; Yadav, S.K, Self-learning materials for teacher educators. Vol. 1. New Delhi, NCERT, 1998.

[4] Arora, G.L.; Ray Shefali. Towards an enlightened human resource in education. New Delhi, State Council of Educational Research and Training, 1993.

[5] Ayres, Ed. (1999). Gods last offer: Negotiating with Sustainable future (pp. 1-45). New york: Four walls Eight Windows.

[6] Ballantyne, R. R, \& Packer, J.M (1996). Teaching and Learning in environmental education: Developing environmental conceptions. The Journal of Environmental Education, 27(2), 25-33.

[7] Barraza, L., \& Walford, R.A (2002). Environmental education: A comparison between English and Mexican School children. Environmental Education Research, 8, 171-186.

[8] Curriculum Board for Secondary Education. Scheme of comprehensive school-based evaluation. New Delhi, Government of India, n.d.

[9] Government of India. Operationalization of the suggestions for teacher fundamental duties to the citizens of the country. Interim report. New Delhi, 1999.

[10] Ministry of Human Resource Development, Department of Education. Minimum levels of learning at the primary stage. New Delhi, Government of India, 1991.

[11] Successful models of environmental education in urban schools with a special focus on sustainability project proposal by centre for environmental research and education (CERE)
[12] Ministry of Human Resource Development. National policy on education. New Delhi, Government of India, 1986.

[13] National Advisory Committee, Ministry of Human Resource Development. Learning without burden. New Delhi, Government of India, 1993. National Council of Educational Research and Training.

[14] National curriculum for elementary and secondary education. A framework. New Delhi, Government of India, 1988.

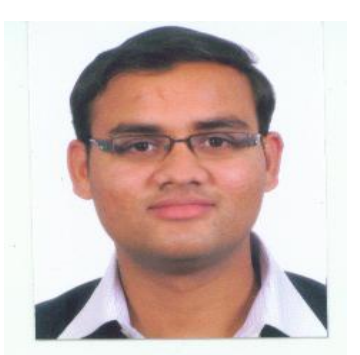

An engineering graduate in (Petro-Chemical Engineering) with additional M.Tech. in Environmental Science \& Engineering from Indian School of Mines (ISM), Dhanbad with over $7+$ years of proven credentials in EHS Management, Project

Management, ISO 14001 \& OHSAS 18001 implementation and Statutory Compliances in the manufacturing (large scale integrated aluminium plants, oil and gas, automobiles, non-ferrous - Zinc \& lead) \& and service sector.

Presently working with Saudi Arabia Mining Company as Environment Specialist and EHS -Trainer. Prior to that was designated as Associate in ESG at Morgan Stanley Capital International (MSCI).I have Published more than two dozen papers in several National and International conventions and journals. I am also a National Expert in Clean Technology and examiner for various Awards like IMC RBNQ Award, Qimpro Award, and CII-ITC Sustainability Award. He also regularly conduct seminars and in-house workshops on Human Performance and motivate teams in optimizing their performance levels \& possess excellent analytical, organizational \& interpersonal skills.

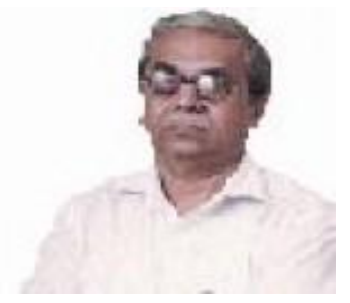

Presently a Professor in Department of Management Studies, Indian School of Mines, Dhanbad, Dr Pathak started his academic career as a lecturer in Faculty of Management Studies, Banaras Hindu University after a short stint in the industry.

Moving to ISM in 1991, he occupied different positions in the hierarchy. As a researcher, consultant, trainer and academic, Dr Pathak has wide experience of Indian and abroad. He is also a contributor to various national dailies and periodicals writing on socio - political and managerial issues. He contributes a regular column on Spirituality in national daily 'The Pioneer'. He also is associated with various professional bodies and associations and is the President of the local Management Association affiliated to AIMA 